\title{
Perinatal Outcome in Hypertensive Disorder of Pregnancy - A Retrospective Study from a Tertiary Care Teaching Hospital
}

\author{
Mustafa Captain, Sanjay Natu*, Sameer Mhatre, Anjali Parekh, Manas Kumar Behera \\ Department of Paediatrics, Smt Kashibai Navale Medical College \& General Hospital, Pune, India \\ Email address: \\ drmustafacaptain@gmail.com (M. Captain),sanjaynatu@gmail.com (S. Natu), sameerjjh@yahoo.com (S. Mhatre), \\ dranjaliparekh83@gmail.com (A. Parekh),manasbehera1952@gmail.com (M. K. Behera) \\ ${ }^{*}$ Corresponding author
}

\section{To cite this article:}

Mustafa Captain, Sanjay Natu, Sameer Mhatre, Anjali Parekh, Manas Kumar Behera. Perinatal Outcome in Hypertensive Disorder of Pregnancy - A Retrospective Study from a Tertiary Care Teaching Hospital. American Journal of Pediatrics. Vol. 6, No. 1, 2020 , pp. $52-57$. doi: 10.11648/j.ajp.20200601.19

Received: January 22, 2020; Accepted: February 18, 2020; Published: February 26, 2020

\begin{abstract}
Hypertensive disorder of pregnancy (HDP) is a multisystem disorder of pregnancy known to jeopardize safe pregnancy thereby increasing the maternal and neonatal morbidity and mortality. A retrospective observational study of nine months duration was conducted to determine the fetal and early neonatal outcome in pregnancies complicated with HDP in a tertiary care hospital. Result: 163 women with HDP delivered during the study period. Out of total 163 births, perinatal deaths occurred in $18(11.04 \%)$ cases, of which $10(6.13 \%)$ were stillbirth and $8(5.23 \%)$ were early neonatal death thus making a perinatal mortality rate of 110 per 1000 births. Low birth weight and preterm delivery occurred in $71(43.56 \%) \& 42(25.77 \%)$ respectively. Amongst the $53(32.52 \%)$ neonates who required admission to the NICU, $37(69.8 \%)$ neonates had respiratory distress including $23(43.4 \%)$ neonates' requiring ventilatory support. Occurrences of adverse perinatal outcomes were significantly higher in eclampsia \& preeclampsia as compared to gestational HTN except for metabolic abnormalities. Conclusion: There is a significant burden of perinatal mortality and morbidity more so with pre-eclampsia \& eclampsia. The findings of this study can represent an evidence for healthcare providers and policy makers in devising more appropriate interventions for in utero transfer of women with HDP so as to improve perinatal outcomes.
\end{abstract}

Keywords: Hypertensive Disorders of Pregnancy, Perinatal Morbidity, Perinatal Mortality

\section{Introduction}

Hypertensive disorder of pregnancy (HDP) is one of the most common medical problems encountered in pregnancy $[1,2]$. It is a multisystem disorder of pregnancy known to increase the maternal and neonatal morbidity and mortality, thus making it a significant global health issue [3, 4]. HDP occurs in about $10 \%$ of all pregnant women around the world [5].

The adverse perinatal outcomes associated with hypertensive disorders are generally referable to placental insufficiency, placental abruption, hypoxia and prematurityrelated complications. Foetal complications are linked to the severity of preeclampsia and eclampsia. Perinatal mortality which includes stillbirth and early neonatal death are also seen to be increased HDP [6-8].

Perinatal mortality is a key indicator of maternal care and a reflection of the quality of obstetric and pediatric care available in a country. Global perinatal mortality rate (PMR) is estimated to be 47 per 1000 birth with excessively wide disparity between the developed and less developed regions [9]. Apart from perinatal mortality, significant neonatal morbidities in the form of low birth weight, intrauterine growth restriction (IUGR), preterm birth, respiratory distress requiring neonatal intensive care unit (NICU) admission are seen with greater frequencies in HDP. Similarly, long term morbidities in the form of developmental consequences are also known [10].

As compared to the literature on maternal outcomes in HDP, there is a relative dearth of data from Indian setting on 
effect of HDP on perinatal outcome. Hence this study was planned to evaluate the spectrum of perinatal morbidities and mortality in Hypertensive disorders of pregnancy.

\section{Objectives}

The objective of the study was to determine the perinatal outcomes of hypertensive disorders among pregnant women who obtained maternity and childbirth services in a tertiary care hospital.

\section{Material and Methods}

\subsection{Type of Study}

This retrospective observational study was carried out in the department of Paediatrics after permission from the institutional ethics committee.

\subsection{Inclusion Criteria}

All women with hypertensive disorders of pregnancy with singleton pregnancy delivered at our tertiary care hospital between September 2017 to May 2018 were included in the study.

\subsection{Exclusion Criteria}

1. Women with gestational diabetes mellitus (GDM).

2. Women with chronic diseases like chronic renal failure, chronic liver disease, endocrine diseases \& collagen disease.

3. Women with twin gestations.

The study was approved by institutional ethics committee (Approval Letter Ref: SKNMC/Ethics/App/2018/422).

\subsection{Data Collection}

Data collection was done by reviewing case files of all women with HDP who delivered during the study period. The baseline medical records of the included mothers and their babies were reviewed to determine the perinatal outcome of relevance to the study.

\subsubsection{Maternal Data}

The maternal data included demographic parameters like maternal age, gravida, parity, number of antenatal visits, gestational age (determined by last menstrual period or $1 \mathrm{st}$ trimester ultrasound), type of maternal hypertensive disorder of pregnancy (according to the criteria adopted from national high blood pressure education program - NHBPEP). Intrapartum data like preterm onset of labour, mode of delivery, need for instrumentation and indication of caesarean birth if any, were noted.

\subsubsection{Perinatal and Neonatal Data}

Perinatal outcome indicators including stillbirths and early neonatal deaths were documented. Low birth weight was classified as birth weight less than $2500 \mathrm{~g}$ irrespective of gestational age, sex, race and clinical features according to World Health Organization [11]. Babies whose birth occurred before completing 37 gestational weeks or 259 days of gestation were classified as preterm [12]. Neonatal morbidities like admission to NICU, APGAR score at $1^{\text {st }} \&$ $5^{\text {th }}$ minute, respiratory distress, need for respiratory supports like of NCPAP or ventilator care, necrotizing enterocolitis (NEC), sepsis, metabolic abnormalities and various other morbidities were documented [6-8]. Gestational age was estimated clinically by New Ballad's scoring. Outcome at the time of discharge and cause of death in case of death were documented.

\subsection{Statistical Analysis}

Data analysis was done using WinPepi, Epi7 and SPSS version 20. The results were presented in percentages where necessary and appropriate measures of centrality (mean) and dispersion (standard deviation) were calculated. Univariate and multivariate analyses were also performed using test of significance like chi-square test or Fisher's exact test. Pvalues less than 0.05 were considered significant.

\section{Results}

There were 180 women with HDP who satisfied inclusion criteria during the study period. However, 17 subjects were excluded for various reasons including associated maternal conditions like diabetes mellitus, hypothyroidism (5 each), twin gestation $(n=4)$, and other chronic conditions like chronic liver, renal or collagen diseases $(n=7)$. Thus, a total of 163 women were included in the study.

The mean maternal age was 24.76 years. The data showed that $77(47.23 \%)$ women had gestational hypertension, 74 $(45.39 \%)$ had preeclampsia and $12(7.36 \%)$ had eclampsia. Full term delivery was seen in $121(74.23 \%)$ and preterm delivery in $42(25.77 \%)$. The mean gestational age and birth weight at the time of delivery was $37.4 \pm 3.01$ weeks \& $2486.3 \pm 741.6$ grams respectively. Cesarean birth occurred in 77 (47.23\%) hypertensive mothers, commonest indication being fetal distress in $29(37.66 \%)$, followed by previous cesarean birth in $21(27.27 \%)$ and impending eclampsia in 13 (16.88\%). The maternal demographic and obstetric characteristics are as shown in Table 1.

Table 1. Basic demographic and obstetrical data of the hypertensive mother.

\begin{tabular}{llllll}
\hline Parameters & Variables & $\begin{array}{l}\text { GESTATIONAL HTN } \\
(\mathbf{N}=\mathbf{7 7})\end{array}$ & $\begin{array}{l}\text { PREECLAMPSIA } \\
(\mathbf{N}=\mathbf{7 4})\end{array}$ & ECLAMPSIA (N+12) & Total (N=163) \\
\hline \multirow{3}{*}{ Age Group } & $<19$ & $1(1.3)$ & $2(2.7)$ & $0(0)$ & $3(1.84 \%)$ \\
& $19-34$ & $73(94.81)$ & $71(95.95)$ & $12(100)$ & $156(95.70 \%)$ \\
\hline
\end{tabular}




\begin{tabular}{llllll}
\hline Parameters & Variables & $\begin{array}{l}\text { GESTATIONAL HTN } \\
(\mathbf{N}=\mathbf{7 7})\end{array}$ & $\begin{array}{l}\text { PREECLAMPSIA } \\
(\mathbf{N = 7 4 )}\end{array}$ & ECLAMPSIA (N+12) & Total (N=163) \\
\hline \multirow{3}{*}{ Gravidity } & 1 & $39(50.65)$ & $30(40.54)$ & $7(58.33)$ & $76(46.62 \%)$ \\
& $2-4$ & $38(49.35)$ & $42(56.76)$ & $5(41.67)$ & $85(52.15 \%)$ \\
\multirow{3}{*}{ Parity } & $=>5$ & $0(0)$ & $2(2.7)$ & $0(0)$ & $2(1.23 \%)$ \\
& 0 & $41(53.25)$ & $32(43.24)$ & $8(66.67)$ & $81(49.69 \%)$ \\
& $1-3$ & $36(46.75)$ & $42(56.76)$ & $4(33.33)$ & $82(50.31 \%)$ \\
Antenatal Visits & $=>4$ & $0(0)$ & $0(0)$ & $0(0)$ & 0 \\
& 0 & $4(5.19)$ & $8(10.81)$ & $4(33.33)$ & $16(9.82 \%)$ \\
& $=>4$ & $25(32.47)$ & $31(41.89)$ & $4(33.33)$ & $60(36.81 \%)$ \\
\end{tabular}

Table 2 shows the occurrence of perinatal mortality among the different categories of hypertensive disorders. There occurred 18 perinatal deaths including 10 stillbirths and 8 early neonatal deaths, making a perinatal mortality rate (PMR) of 110 per 1000 births in our study. Of the 10 still birth, $6(60 \%)$ were preterm and $4(40 \%)$ were term. The majority $(75 \%)$ of early neonatal deaths occurred in preterm babies. Amongst the eight early neonatal deaths, respiratory distress syndrome accounted for three, meconium aspiration syndrome for two, and NEC, birth asphyxia and intraventricular hemorrhage for one each. The perinatal mortality was statistically higher in pre-eclampsia and eclampsia groups.

Table 2. Perinatal mortality outcomes among women with Hypertensive disorder of pregnancy.

\begin{tabular}{lllll}
\hline $\begin{array}{l}\text { Perinatal mortality } \\
\text { indicators }\end{array}$ & $\begin{array}{l}\text { GESTATIONAL } \\
\text { HTN n=77 }\end{array}$ & $\begin{array}{l}\text { PREECLAMPSIA } \\
\mathbf{n = 7 4}\end{array}$ & ECLAMPSIA n=12 & Total 163 \\
\hline FSB & $1(1.3)$ & $7(9.46)$ & $2(16.67)$ & $10(6.13)$ \\
Early neonatal death & $0(0)$ & $5(6.76)$ & $3(25)$ & $8(5.23)$ \\
Perinatal Mortality & $1(1.3)$ & $12(16.22)$ & $5(41.67)$ & 0.0149 \\
\hline
\end{tabular}

Table 3 represents the frequencies of various perinatal morbidities amongst the different categories of hypertensive disorders. Overall at least one adverse perinatal outcome was observed in $100(61.3 \%)$ subjects. The occurrence of various adverse perinatal morbidities was significantly higher in eclampsia and preeclampsia as compared to gestational HTN except for metabolic abnormalities.
The most common adverse perinatal outcome observed was low birth weight followed by prematurity. Amongst the neonates admitted to NICU, 37 (69.8\%) neonates had respiratory distress including 23 neonates' who required ventilatory support. Out of 55 (33.74\%) babies whose APGAR score was less than 7 at $1 \mathrm{~min}$, $36(22.09 \%)$ continued to have APGAR score less than 7 at $5 \mathrm{~min}$ in spite of appropriate resuscitation efforts.

Table 3. Perinatal morbidity outcomes among women with Hypertensive disorder of pregnancy ( $p$ value $<0.05$ is considered as statistically significant as obtained by pearson chi square).

\begin{tabular}{|c|c|c|c|c|c|}
\hline Perinatal morbidity indicators & $\begin{array}{l}\text { GESTATIONAL } \\
\text { HTN } \mathbf{n}=77\end{array}$ & $\begin{array}{l}\text { PREECLAMPSIA } \\
\mathrm{n}=74\end{array}$ & $\begin{array}{l}\text { ECLAMPSIA } \\
\mathrm{n}=12\end{array}$ & Total $N=163$ & p value \\
\hline $\begin{array}{l}\text { Atleast one adverse perinatal } \\
\text { outcome }\end{array}$ & $38(49.35)$ & $51(52.70)$ & $11(91.67)$ & $100(61.35)$ & 0.0033 \\
\hline Admission to NICU & $18(23.38)$ & $28(37.84)$ & $7(58.33)$ & $53(32.52)$ & 0.023 \\
\hline Respiratory Distress & $9(11.69)$ & $21(28.38)$ & $7(58.33)$ & $37(22.70)$ & $<0.001$ \\
\hline Need for mechanical ventilation & $3(3.9)$ & $15(20.27)$ & $5(41.67)$ & $23(14.11)$ & $<0.001$ \\
\hline Low birth weight & $23(29.87)$ & $41(55.41)$ & $7(58.33)$ & $71(43.56)$ & 0.004 \\
\hline APGAR score $<7$ at $1 \mathrm{~min}$ & $19(24.68)$ & $29(39.19)$ & $7(58.33)$ & $55(33.74)$ & 0.001 \\
\hline APGAR score $<7$ at $5 \mathrm{~min}$ & $7(9.09)$ & $22(29.73)$ & $7(58.33)$ & $36(22.09)$ & $<0.001$ \\
\hline Sepsis & $4(5.19)$ & $16(21.62)$ & $5(41.67)$ & $25(15.34)$ & 0.001 \\
\hline Thrombocytopenia & $2(2.6)$ & $14(18.92)$ & $4(33.33)$ & $20(12.27)$ & 0.001 \\
\hline NEC & $2(2.6)$ & $9(12.16)$ & $3(25)$ & $14(8.59)$ & 0.012 \\
\hline Feed Intolerance & $6(7.79)$ & $17(22.97)$ & $3(25)$ & $26(15.95)$ & 0.026 \\
\hline Shock & $4(5.19)$ & $19(25.68)$ & $6(50)$ & $29(17.79)$ & $<0.001$ \\
\hline
\end{tabular}

\section{Discussion}

Hypertensive disorder of pregnancy is considered as one of the major risk factors for perinatal morbidity and mortality especially in the developing world. The current PMR of India is 36/1000 birth according to NFHS 2015-16 report [13]. In the present study expectedly, the PMR was $110 / 1000$ birth.
As seen in table 4, the results obtained in our study are comparable to the results found in various similar studies around the globe [14-19]. In the present study, all except one perinatal death occurred in mothers with eclampsia and preeclampsia. The higher incidence of perinatal mortality is related to the severity of hypertensive disease in pregnancy. This could be because of uteroplacental insufficiency, placental abruption, severe intrauterine asphyxia and low 
gestational age $[20,21]$.

Table 4. Comparison of adverse perinatal outcomes in Hypertensive women in various other studies.

\begin{tabular}{|c|c|c|c|c|c|c|}
\hline Similar study & FSB & $\begin{array}{l}\text { Early neonatal } \\
\text { death }\end{array}$ & $\begin{array}{l}\text { Perinatal } \\
\text { Mortality }\end{array}$ & $\begin{array}{l}\text { NEED FOR } \\
\text { NICU }\end{array}$ & LBW & $\begin{array}{l}\text { Preterm delivery } \\
\text { rate }\end{array}$ \\
\hline 1. Present study & $6.13 \%$ & $5.23 \%$ & $110 / 1000$ & $32.52 \%$ & $43.56 \%$ & $25.77 \%$ \\
\hline 2. Kritika Vats et al India [14] & $6 \%$ & $4.3 \%$ & $100 / 1000$ & $25.5 \%$ & $31.6 \%$ & $26.5 \%$ \\
\hline 3. Kwame Adu-B. et al Ghana [15] & $6.8 \%$ & $3.8 \%$ & $106 / 1000$ & $24.7 \%$ & $24.7 \%$ & $21.7 \%$ \\
\hline 4. Yucesoy G et al Turkey [16] & $12.59 \%$ & $2.19 \%$ & $144 / 1000$ & $24.81 \%$ & - & - \\
\hline 5. Wolde Z. et al Ethiopia [17] & - & - & - & $22.5 \%$ & $47.9 \%$ & $31.6 \%$ \\
\hline 6. Olusanya BO et al Nigeria [18] & - & - & - & $27.77 \%$ & $31.02 \%$ & $46.29 \%$ \\
\hline
\end{tabular}

Low birth weight and prematurity which are the real distressing problem in babies of hypertensive mothers were amongst the commonest adverse perinatal outcomes in babies of hypertensive mother. The other important adverse perinatal outcome determined were need for NICU admission, NEC and low APGAR score amongst others. Table 4 shows the outcome in few similar studies which were comparable. Low birth weight babies are at a much higher risk of dying than babies with birth weight $>2500 \mathrm{~g}[22,23]$. Apart from increased mortality, it has been observed that these babies have long-term neurological disabilities, impaired language and academic achievement along with greater predisposition to chronic illness including cardiovascular disease and diabetes [24]. Premature infants are predisposed to increased oxidative stress and prematurity is one of the leading causes of all under-5 child mortality worldwide. This is due to immature multiple organ systems leading to respiratory distress, sepsis, intracranial haemorrhage and NEC [25].

NICU admission rate was significantly higher in the women with preeclampsia and eclampsia compared to gestational hypertension. Admission to NICU is often associated with more morbidity in the neonates, not to mention the financial implications to the parents as well as the emotional stress due to separation of the baby from the mother.

In our study, around one fourth of the babies had either feeding intolerance or NEC. A higher incidence of $(40 \%)$ neonates who had feeding intolerance and pre-NEC/NEC was documented in a similar study by Hassan M et al [19]. Higher rate of NEC in maternal hypertension can be attributed to the common patho-physiology of hypoxia/ischemia between maternal disease and fetal complication [21].

Low APGAR score $(<7)$ at $1^{\text {st }}$ and $5^{\text {th }}$ min were statistically more common in the eclamptic and pre-eclamptic group. Improvement in the APGAR scores at 5 min amongst the various types of hypertensive disorders might be partly attributed to an effective neonatal resuscitation. Both APGAR score at $1^{\text {st }}$ and $5^{\text {th }}$ min was comparable to results seen in various other studies [14, 15, 17, 26-28]. Adequate preparation with personnel trained in neonatal resuscitation is essential for all deliveries, more so ever in deliveries of hypertensive women. However, it must be noted that there was no improvement in the APGAR score of babies born to eclamptic mother with low $(<7)$ initial APGAR score at birth despite adequate resuscitation.

Considering the high perinatal mortality and morbidities associated in hypertensive pregnant women, there is a pressing need to improve the perinatal health measures. The present study was conducted in a tertiary care centre with trained personnel available round the clock for managing maternal condition as well neonatal problems including efficient resuscitation. The outcome is likely to be worse in peripheral centres where facilities and trained manpower are often limited. One of the most important measures to improve outcomes in these situations would be early referral from primary centres to centres with optimum maternal and neonatal facilities as soon as maternal hypertension is detected. Strong evidence to suggest that planned delivery when compared with expectant management reduces maternal morbidity and severe hypertension has been shown in a recent study. However, planned delivery led to more neonatal unit admissions but without any greater respiratory or other neonatal morbidity, intensity of care, or length of stay. Therefore this impact should be discussed with women with late preterm preeclampsia, helping her make an informed decision on timing of delivery [29].

Amongst the few limited therapeutic options that are available for optimizing the perinatal outcome while managing women with HDP, antenatal administration of corticosteroid is recommended for women at risk of imminent preterm delivery. A significant reduction in neonatal death and neonatal morbidity occurs in infants of mothers with hypertensive disorders exposed to antenatal corticosteroids [30, 31]. Another important strategy would be appropriate and early administration of magnesium sulphate for prevention of cerebral palsy in the infant and child due to its neuroprotective effect on preterm infants, apart from its common use for seizure prophylaxis in women with preeclampsia [31-33].

This study adds to the limited data available focusing on short term neonatal outcomes in hypertensive disorder of pregnancy since most of the studies on hypertensive disorders of pregnancy have focused on the maternal outcomes. A retrospective study design and a lack of control group re obvious limitations of the study and a larger prospective study with a control group will go a long way in confirming these findings. 


\section{Conclusion}

There is a significant burden of perinatal mortality and morbidity associated with HDP, more so with pre-eclampsia $\&$ eclampsia. HDP remains a great challenge for an obstetrician and neonatologist due to difficult antenatal care involving a complex balance between the maternal risks of continuing pregnancy and the fetal risks of delivering premature\&/or LBW baby. It is essential at primary health care level that these cases are suspected, diagnosed and referred to tertiary care centreat the earliest so as to ensure optimum maternal and perinatal outcome. This is important because adverse perinatal mortality is not only a key indicator of maternal care but also a reflection of the quality of neonatal care available in a country.

\section{Conflict of Interest}

The authors declare no conflict of interest.

\section{Acknowledgements}

The authors are thankful to head of the department of Obstetrics \& Gynaecology and Paediatrics, for allowing us to carry out this study in this institution. We would like to thank our intern Dr. Swasti Deshpande and our senior statistician Dr. S. L. Jadhav for their valueable output.

\section{References}

[1] Kauntiz A. M, Hughes J. M, Grimes D. H, Smith J. C, Rochat R. W and Kaffrissen M. E. Causes of maternal mortality in the United States of American. Journal of Obstetrics and Gynecology 1985; 65: 605-12.

[2] Wallis AB Saftlas AF, Hsia J, Atrash HK, Secular trends in rates of preeclampsia, eclampsia and gestational hypertension, United States, 1987-2004. Am J Hypertens 2008; 21: 521-6.

[3] American College of Obstetricians and Gynecologists (ACOG). Practice bulletin No. 33: Diagnosis and management of preeclampsia and eclampsia. Obstet Gynecol. 2002; 99: 159-67.

[4] Gifford RW, August PA, Cunningham G, Green LA, Lindheimer MD, McNellisD, Roberts JM, Sibai BM, Taler SJ. Report of the National High Blood Pressure Education Program Working Group on High Blood Pressure in Pregnancy. Am J Obstet Gynecol. 2000; 183: S1-S22.

[5] National health portal (2016) Preeclampsia. Available at: https://www.nhp.gov.in/disease/gynaecology-andobstetrics/preeclampsia [Accessed 3 Oct. 2019].

[6] Brown MA, Hague WM, Higgins J, Lowe S, McCowan L, Oats J, Peek MJ, Rowan JA, Walters BN; Austalasian Society of the Study of Hypertension in Pregnancy. The detection, investigation and management of hypertension in pregnancy: full consensus statement. Aust N Z J ObstetGynaecol. 2000; 40 (2): 139-55.

[7] Hofmeyr GJ, Belfort M. Proteinuria as a predictor of complications of pre-eclampsia. BMC Medicine. 2009; 7: 11.
[8] Bhide A, Arulkumaran S, Damania KR, Daftary SN. In: Arias' practical guide to high-risk pregnancy and delivery a south Asian perspective. Chapter 13, Hypertensive disorders in pregnancy. $4^{\text {th }}$ ed. Haryana: Reed Elsevier India Private Limited; 2015: 185-232.

[9] World Health Organization (2006) Neonatal and perinatal mortality: country, regional and global estimates. Available at: http://apps.who.int/iris/handle/10665/43444 [Accessed 3 Oct. 2019].

[10] Duley L. The global impact of pre-eclampsia and eclampsia. Semin Perinatol. 2009; 33: 130-7.

[11] World Health Organization (2004) ICD-10: International statistical classification of diseases and related health problems: tenth revision, $2^{\text {nd }}$ edition. Available at: https://apps.who.int/iris/handle/10665/42980 [Accessed 3 Oct. 2019].

[12] World Health Organization (2012) Born Too Soon: the global action report on preterm birth, New York.

[13] National Family Health Survey (2017). Available at: http://rchiips.org/nfhs/ [Accessed 3 Oct. 2019].

[14] Vats K et al. Study of fetal outcome in hypertensive disorders of pregnancy in a tertiary care maternity hospital of Delhi. Int J Reprod Contracept Obstet Gynecol. 2016; 5 (11): 37733777.

[15] Adu-Bonsaffoh et al. Perinatal outcomes of hypertensive disorders in pregnancy at a tertiary hospital in Ghana. BMC Pregnancy and Childbirth. (2017); 17: 388.

[16] Yucesoy G, Ozkan S, Bodur H, Tan T, Calişkan E, Vural B, Corakçi A. Maternal and perinatal outcome in pregnancies complicated with hypertensive disorder of pregnancy: a seven year experience of a tertiary care center. Arch Gynecol Obstet. 2005; 273 (1): 43-9.

[17] Wolde Z, Segni H, Woldie M. Hypertensive disorders of pregnancy in Jimma University specialized hospital. Ethiop J Health Sci. 2011; 21 (3): 147-53.

[18] Olusanya BO, Solanke OA. Perinatal outcomes associated with maternalhypertensive disorders of pregnancy in a developing country. Hypertension in Pregnancy. 2012; 31 (1): $120-30$.

[19] Hassan M, Choudhury F, Begum M, Rahman H, Akhter S. Immediate Perinatal Outcome of Neonates with Maternal Hypertensive Disorders in Pregnancy. J Nepal Paediatr Soc. 2013; 33 (3): 190-5.

[20] P. Ade-Ojo and O. M. Loto. Outcome of eclampsiaat the obafemiawolowo university teaching hospital complex, ILEIFE. Nigerian Journal of Clinical Practice. 2008; 11 (3): 279-84.

[21] Shah DM: Perinatal implications of maternal hypertension. SeminPediatrNeurol 2001; 8: 108-119.

[22] Kramer MS. Determinants of low birth weight: methodological assessment and meta-analysis. Bull World Health Organ 1987; 65 (5): 663-737.

[23] Badshah S, Mason L, McKelvie K, Payne R, Lisboa PJ. Risk factors for low birthweight in the public-hospitals at Peshawar, NWFP-Pakistan. BMC Public Health. 2008; 8: 197. 
[24] Zerbeto AB, Cortelo FM, Élio Filho BC. Association between gestational age and birth weight on the language development of Brazilian children: a systematic review. Jornal de Pediatria. 2015; 91 (4): 326-32.

[25] You D, Hug L, Ejdemyr S, Idele P, Hogan D, Mathers C, et al. Global, regional, and national levels and trends in under-5 mortality between 1990 and 2015, with scenario-based projections to 2030: a systematic analysis by the UN Interagency Group for Child Mortality Estimation. The Lancet. 2015; 386 (10010): 2275-86.

[26] Fatemeh T, Marziyeh G, Nayereh G, Anahita G, Samira T. Maternal and perinatal outcome in nulliparous women complicated with pregnancy hypertension. J Pak MedAssoc. 2010; 60: 707-10.

[27] Sachan R, Patel ML, Sachan P, Gaurav A, Singh M, Bansal B. Outcomes in hypertensive disorders of pregnancy in the north Indian population. Int J Womens Health. 2013; 5: 101-8.

[28] Doddamani GB, Doddamani UG. Perinatal outcome in preeclampsia: A prospective study. Sch. J. App. Med. Sci. 2014; 2 (1C): 291-3.

[29] Chappell LC, Brocklehurst P, Green ME, Hunter R, Hardy P,
Juszczak E, et al. Planned early delivery or expectant management for late preterm pre-eclampsia (PHOENIX): a randomised controlled trial. The Lancet. 2019; 394 (10204): 1181-1190.

[30] M. R. Laye and E. H. Dellinger, "Timing of scheduled cesarean delivery in patients on a teaching versus private service: adherence to American College of Obstetricians and Gynecologists guidelines and neonatal outcomes," American Journal of Obstetrics and Gynecology. 2006; 195 (2): 577-82.

[31] World Health Organization (2015) WHO recommendations on interventions to improve preterm birth outcomes: executive summary. Available at: https://apps.who.int/iris/handle/10665/204270 (Accessed 3 Oct. 2019).

[32] L. W. Doyle, C. A. Crowther, P. Middleton, S. Marret, and D. Rouse, "Magnesium sulphate for women at risk of preterm birth for neuroprotection of the fetus," Cochrane Database of Systematic Reviews. 2009; 1: CD004661.

[33] D. J. Rouse, D. G. Hirtz, E. Thom et al., "A randomized, controlled trial of magnesium sulfate for the prevention of cerebral palsy," The New England Journal of Medicine. 2008; 359 (9): 895-905. 